\title{
Efeitos das Variações Cambiais sobre os Preços da Carne de Frango no Brasil entre 2008 e 2012
}

\author{
Carlos Eduardo Caldarelli ${ }^{1}$ e Marcia Regina Gabardo da Camara ${ }^{2}$
}

Resumo: Este artigo investiga a relação entre a taxa de câmbio real e os preços da carne de frango no Brasil, no período de 2008 a 2012. Para tanto, foi estimado um modelo Vetorial de Correção de Erros (VEC). Os resultados apontam a existência de uma relação de longo prazo estável entre a evolução do nível da taxa de câmbio real e o preço da carne de frango congelada - cointegração. Entretanto, as evidências acerca da sensibilidade dos preços da carne de frango em relação às variações na taxa de câmbio real, para o período analisado, são fracas. Por outro lado, o estudo sugere a causalidade no sentido inverso, ou a existência de commodity currency. O trabalho evidencia a importância da análise dos efeitos dos preços do frango congelado sobre a taxa de câmbio no período recente no Brasil.

Palavras-chaves: Taxa de câmbio, preços de commodities, avicultura, causalidade de Granger, VEC.

Abstract: This paper investigates the ratio between real exchange rate and chicken meat
prices in Brazil, from 2008 to 2012. The Vector Error Correction Model (VECM) was
applied. The results show a long-run ratio between the real exchange rate and the frozen
broiler price - cointegration. However, evidences of the chicken meat price sensibility to
the exchange rate are weak for the analyzed period. On the other hand, the paper suggests
the evidence of the commodity currency. The paper highlights the importance of analyzing
effects of the frozen chick meat on exchange rate in Brazil in the recent period.

Key-words: Exchange rate, commodities prices, poultry, Granger causality, VECM.

Classificação JEL: F31, C32.

1 Professor Adjunto do Departamento de Economia da Universidade Estadual de Londrina (PR). E-mail: carlos.caldarelli@gmail.com

2 Professora Associada do Departamento de Economia da Universidade Estadual de Londrina (PR). E-mail: mgabardo@uel.br 


\section{Introdução}

O objetivo deste estudo é avaliar a relação entre taxa de câmbio real e os preços da carne de frango no Brasil, no período de 2008 a 2012. O estudo busca mensurar o grau de pass-through entre a taxa de câmbio real e os preços da carne de frango. Para tanto, procede-se à estimação de um modelo Vetorial de Correção de Erros (VEC). Os resultados obtidos devem garantir subsídios às análises acerca do processo de formação dos preços da carne de frango.

O Brasil apresenta-se como um dos principais exportadores mundiais de produtos agrícolas e com tendência de elevação no período recente (FAO, 2012). Dados do Mapa (2011) revelam um aumento da participação brasileira nas exportações agrícolas mundiais de 4,7\%, em 2001, para $7,3 \%$, em 2009. Trata-se de uma elevação de 2,6 pontos percentuais em menos de uma década. Nesse mesmo período, as exportações agrícolas ampliaram a sua participação de $28,5 \%$ para $35,8 \%$ no total dos embarques brasileiros.

Em relação ao desempenho do agronegócio exportador, observa-se, na última década (2001/2011), um crescimento médio anual em praticamente todos os setores agrícolas; contudo, o aumento não ocorreu de forma homogênea. Destacam-se os setores como animais vivos, complexo sucroalcooleiro, cereais e carnes, que apresentaram crescimento bem acima da média dos demais. Em termos de quantum exportado, em 2011, os complexos soja, sucroalcooleiro e carnes foram responsáveis por mais de $70 \%$ das exportações agrícolas brasileiras (MDIC/SECEX, 2012).

Neste contexto, tem-se que o forte crescimento das exportações agrícolas ocorreu, principalmente, em função da quantidade exportada, entretanto, não se desconsidera a relevância do aumento dos preços (MAPA, 2011). Dados da FAO (2012) revelam que, nos últimos anos, tem existido um forte incremento no preço das commodities em âmbito mundial, tendência que deve se manter dada a pressão existente na demanda por produtos agrícolas. Entretanto, segundo Mapa (2011), uma parte considerável do aumento da receita dos exportadores brasileiros, advinda da expansão dos preços internacionais dos produtos agrícolas, foi consumida pela sobrevalorização da moeda brasileira nos últimos anos.

Um segmento que merece atenção, nesse sentido, é o de carne de frango, em que as exportações - tanto de cortes quanto do frango inteiro - foram impactadas negativamente pela valorização do 
Real frente ao dólar norte-americano. A parcela da carne de aves de corte destinada às exportações representa, em média, 32\% dos abates do Brasil; trata-se de uma importante commodity na pauta de exportações do País. As exportações brasileiras de frango representaram, em 2010, cerca de $40 \%$ dos embarques mundiais e somaram receita cambial de US\$ 6,8 milhões (ABEF, 2012). Ademais, a carne de frango integra a dieta alimentar do brasileiro, fato que justifica a investigação acerca da sensibilidade dos preços neste mercado às variações cambiais/mercado externo.

Assim, com base nas evidências teóricas apresentadas em Dornbusch (1986), Silva e Carvalho (1995), Kannebley Junior (2002), Tejada e Silva (2008) e, mais recentemente, em Correa (2012), de que a taxa real de câmbio desempenha efeitos sobre o setor exportador de um país e seus preços domésticos, o presente estudo busca investigar a relação entre a recente valorização cambial da moeda brasileira frente à moeda norte-americana, e seus impactos sobre os preços domésticos da carne de frango. Neste sentido, justifica-se a análise entre 2008 e 2012, pois neste período se observa uma sobrevalorização do Real frente ao dólar, o que suscita a necessidade de análise dos efeitos de tal situação sobre preços internos.

Este artigo está dividido em sete seções, incluindo esta introdução. Na segunda seção são apresentadas as características do segmento produtor de carne de frango no Brasil. Na sequência, apresentam-se o modelo teórico, na parte três, e os procedimentos metodológicos e dados utilizados nas partes quatro e cinco, respectivamente. A seção seis expõe os resultados e discussões do trabalho. A última seção trata das considerações finais.

\section{Panorama do complexo agroindustrial de carne de frango no Brasil}

A melhora nos indicadores de renda dos países em desenvolvimento, observada nos últimos anos, associada ao aumento na urbanização e ao crescimento populacional, em âmbito mundial, tem impulsionado a demanda por proteínas de origem animal. Assim, a demanda mundial por todos os tipos de carne apresentou trajetória de crescimento no período recente (IPARDES, 2002). Segundo dados da FAO (2012), essa trajetória se manteve na última década e deve continuar crescendo nos próximos anos, impulsionada, principalmente, pelos mercados emergentes.

Neste contexto, o segmento de carnes no Brasil, desde a década de 1980, apresenta elevado dinamismo em termos de produção, consumo e comércio exterior. Em especial, destaca-se o setor avícola, que expandiu bastante nos últimos anos, tanto nos abates quanto nas exportações. Tal movimento está relacionado, entre outros fatores, ao fato de o setor de ser bastante competitivo e integrado ao mercado externo (EMBRAPA, 2011). A Figura 1, a seguir, apresenta a evolução, no período de 2000 a 2010, dos abates e das exportações do setor avícola no Brasil.

A produção de aves de corte no Brasil está concentrada nas regiões Sul e Sudeste - Paraná (26\%), Santa Catarina (20\%), São Paulo (15\%) e Rio Grande do Sul $(14 \%)^{3}$. Como já mencionado, a atividade avícola é bastante competitiva e uma parcela significativa funciona no sistema integrado de produção. As perspectivas para o segmento apontam que a expansão observada recentemente, tanto nos abates quanto nas exportações, deve se manter para os próximos anos (IBGE, 2011). A Figura 1 mostra, também, que as exportações apresentam taxa de crescimento mais elevada que os abates e que a parcela de carne de frango destinada às exportações representa, em média, 32\% dos abates do setor no Brasil.

Tanto no Brasil quanto em nível internacional, o complexo agroindustrial avícola tem se mostrado mais dinâmico que o suinícola e o de carne bovina. Tal dinamismo é explicado, em grande parte, pelos avanços tecnológicos no setor, principalmente nas áreas de genética, nutrição e sanidade. Cabe destacar, também, o importante papel desempenhado pela crescente demanda por carne de frango observada nos últimos anos, reflexo de uma mudança no padrão alimentar de

\footnotetext{
3 Parcelas em relação ao total nacional dos abates em 2010 dados do IBGE (2011).
} 
Figura 1. Evolução do abate e exportações do setor avícola no Brasil (em milhões de toneladas) - de 2000 a 2010

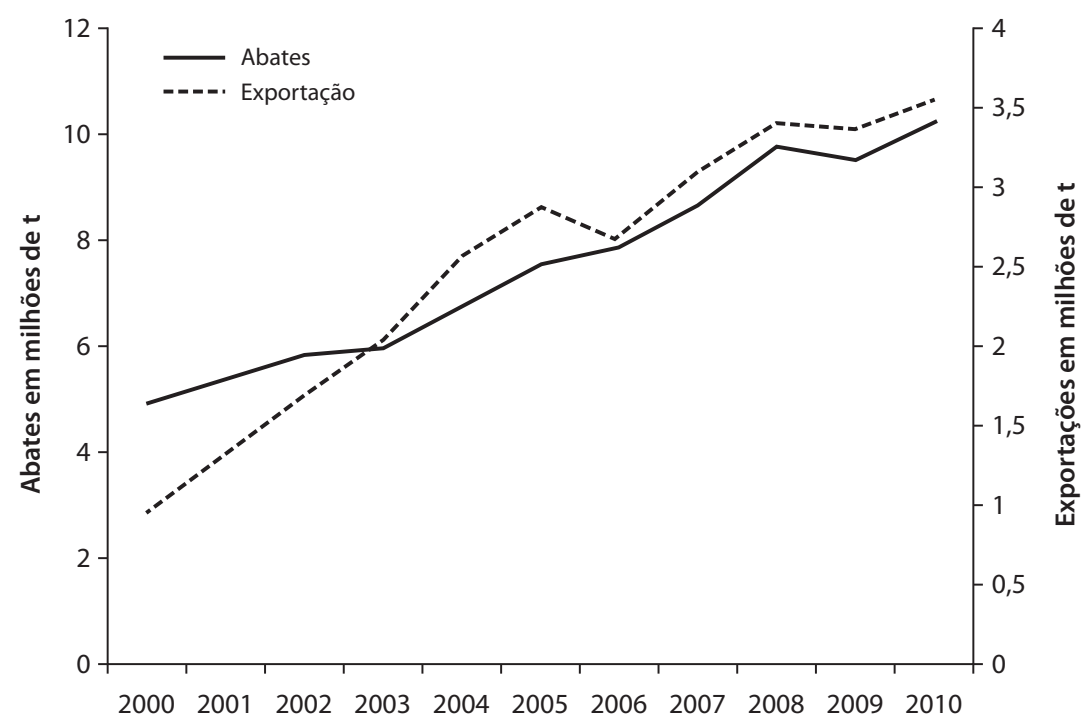

Fonte: Elaborado pelos autores com dados de IBGE (2011) e MDIC/Secex (2012).

substituição de carne vermelha por carne branca (IPARDES, 2002).

No que diz respeito aos preços neste mercado, a Figura 2 apresenta a evolução dos preços do frango vivo (PFV), resfriado (PFR) e congelado
(PFC), no período de janeiro de 2008 a janeiro de 2012 no Brasil.

Observa-se uma oscilação nas séries, principalmente nos preços da carne de frango congelada e resfriada (Figura 2), fato que pode ser justificado

Figura 2. Evolução dos preços do frango vivo, resfriado e congelado - em R\$/kg, de janeiro de 2008 a janeiro de 2012

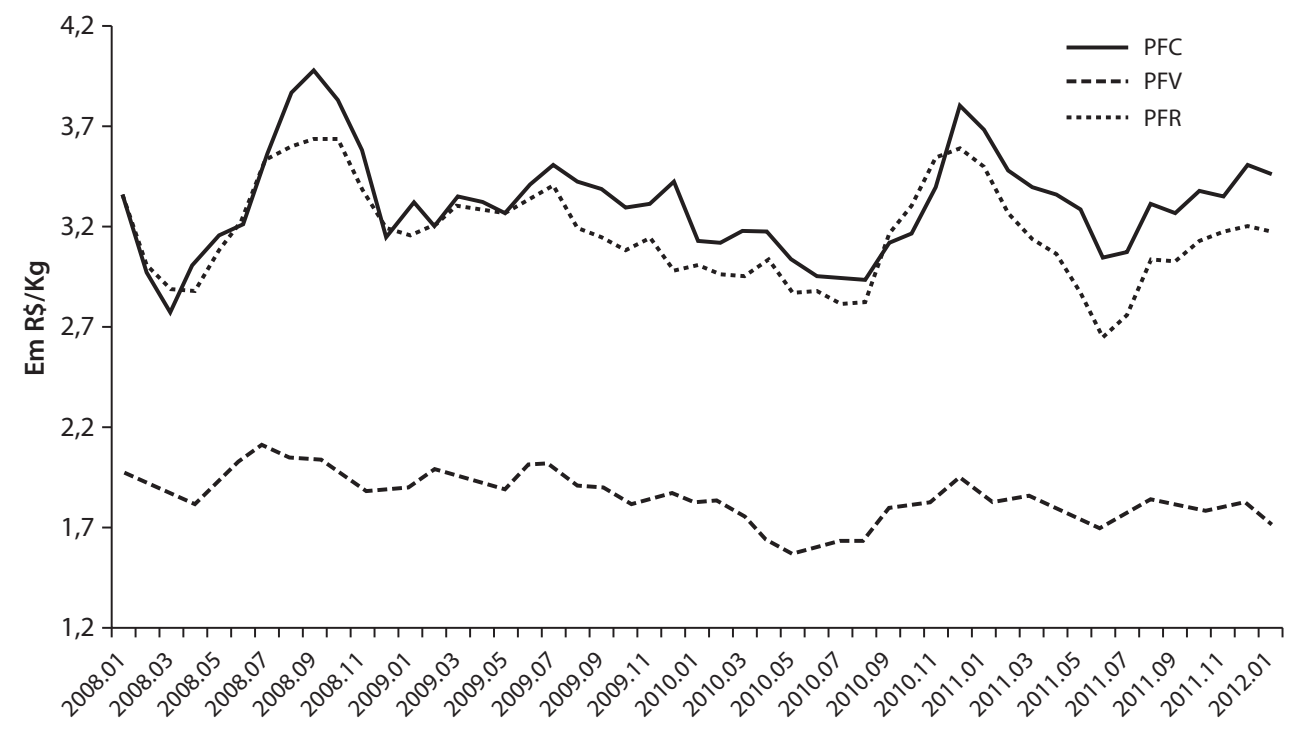

Nota: os valores foram deflacionados com base no IGP-DI (ano base jan/2012=100).

Fonte: Elaborado pelos autores com dados de FGV (2012). 
pela circunstância de grande parte da produção brasileira de carne de frango ser realizada no sistema integrado. Ademais, deve-se destacar que a exportação realizada é predominantemente de carne resfriada e congelada (ABEF, 2012).

Neste mesmo período - 2008 a 2012 -, quando se considera o comportamento da taxa de câmbio real (R\$/US\$), observa-se que os períodos de alta nos preços da carne de frango resfriada e congelada - 03/2008 a 09/2008 e 06/2011 a 01/2012 coincidem com períodos de valorização do Real frente ao dólar, exclusive o período de 12/2010 a 05/2011, em que se observam os preços das principais commodities em queda e a taxa real de câmbio (R\$/US\$) apreciando (o Real) com a entrada de dólares (MAPA, 2011).

Como se trata de um produto cuja parcela significativa é destinada ao mercado interno, cerca de $70 \%$ da produção nacional, acredita-se que, além da expansão na demanda mundial, os preços internos da carne de frango têm sido influenciados pela taxa de câmbio sobrevalorizada no período recente (ABEF, 2012). Dados do Mapa (2011) apontam que, entre 2003 e 2011, o câmbio real (R\$/US\$) teve elevação de aproximadamente $60 \%$, e uma parte dos ganhos dos exportadores tem sido consumida com essa sobrevalorização da moeda.

\section{Modelo teórico}

Este trabalho investiga o papel desempenhado pela taxa de câmbio real sobre os preços domésticos da carne de frango no Brasil, efeito que se convencionou chamar na literatura econômica de exchange rate pass-throught. Evidências empíricas, tais como as apresentadas por Dornbusch (1986), Silva e Carvalho (1995), Tejada e Silva (2008) e Correa (2012), enfatizam o impacto das taxas de câmbio sobre os preços de mercadorias e produtos manufaturados, principalmente em uma economia/setor com algum grau de abertura por via comercial.

Por outro lado, estudos como Kannebley Junior (2002), Bresser-Pereira (2008), Margarido,
Serigati e Perosa (2010), Sonaglio, Zamberlam e Bender Filho (2011) e Veríssimo, Xavier e Vieira (2012) também investigam a relação entre câmbio e setor externo; todavia, levando-se em consideração o quantum exportado.

Em comum a essas duas linhas de estudo, tem-se a investigação entre a política cambial e seus efeitos sobre o comércio exterior, seja via preços, seja quantum exportado. O presente estudo segue estes enfoques, porquanto procura investigar a relação entre o preço de uma mercadoria específica comercializada internacionalmente e a taxa de câmbio real, temática não explorada pelos estudos anteriormente realizados. Doravante, o presente busca evidenciar a relevância da política cambial, não somente para o setor exportador, mas também para os preços domésticos de uma commodity.

O elemento teórico de sustentação leva em consideração que o preço de um bem comercializado no mercado internacional em moeda nacional $(q)$ é o produto do preço em moeda estrangeira $\left(q^{*}\right)$ pela taxa de câmbio nominal $(E)$. Logo, esta relação pode ser expressa por: $q=E . q^{*}$ (DORNBUSCH, 1986).

Segundo Silva e Carvalho (1995), após aplicar o logaritmo neperiano na expressão e diferenciar a equação obtém-se:

$$
\frac{1}{q} d q=\frac{1}{q^{*}} d q^{*}+\frac{1}{E} d E
$$

Que, para pequenas variações, pode ser aproximada por:

$$
\frac{\Delta q}{q}=\frac{\Delta q^{*}}{q^{*}}+\frac{\Delta E}{E}
$$

em que: $\frac{\Delta q}{q}$ é o efeito total do preço, em moeda nacional; $\frac{\Delta q^{*}}{q^{*}}$ é o efeito preço externo; e $\frac{\Delta E}{E}$ é o efeito câmbio.

A expressão (2) mostra que as variações no preço de uma dada commodity, em moeda doméstica, podem ser explicadas pelas variações no preço internacional desta mercadoria e pelas 
variações na taxa de câmbio. Desta forma, o presente estudo busca isolar o efeito câmbio sobre os preços da carne de frango no Brasil, ou exchange rate pass-throught, testando a magnitude da transmissão da taxa de câmbio real sobre os preços da carne de frango vivo, resfriado e congelado.

Segundo Dornbusch (1986), o argumento teórico pode, também, ser formalizado em termos de equilíbrio de oferta e demanda, segundo o qual a relação (2) é expressa em termos de preços e taxas de câmbio real. Considerando-se que $S$ representa a oferta neste mercado; $D$ e $D^{*}$ representam, respectivamente, as demandas domésticas e no exterior; $P$, o nível de preços; $Y$ e $Y^{*}$, o produto doméstico e no exterior, de forma que o equilíbrio entre oferta e demanda neste mercado é dado por:

$$
S=D(q / P, Y)+D^{*}\left(q^{*} / P, Y^{*}\right)
$$

A expressão (3) mostra que, em um determinado país, a demanda por uma commodity é uma função de seu preço real e do nível de atividade. Com base em $q=E . q^{*}$ e a definição de câmbio real como $R=E / E . P^{*}$, substituindo-as na expressão (3), tem-se que o preço real de equilíbrio de uma commodity, para um determinado mercado doméstico é:

$$
q / P=J\left(R, Y, Y^{*}\right)
$$

A relação expressa em (4) mostra que o preço real de uma dada commodity no mercado doméstico é uma função da taxa de câmbio real e do nível de atividade doméstica $(Y)$ e no exterior $\left(Y^{*}\right)$, que representam, respectivamente, a demanda interna e externa neste País. Considera-se, também, que a elasticidade da relação entre preço real de uma mercadoria e taxa real de câmbio será tanto maior quanto menor a participação doméstica na demanda total deste bem (DORNBUSCH, 1986). A magnitude desta transmissão depende das elasticidades da demanda e será uma função crescente da taxa de câmbio real para um país exportador - em presença de uma apreciação real, espera-se um aumento real dos preços.

O estudo de Tejada e Silva (2008) discute esta relação entre as variações da taxa de câm- bio e os repasses - pass-throught - para os preços das exportações dos principais produtos da pauta brasileira. Para os referidos autores, o pass-through das mudanças na taxa de câmbio para os preços das exportações contribui para o grau de competitividade alcançado a partir de variações na taxa de câmbio. Os resultados deste estudo sugerem que há o repasse incompleto dos choques nas taxas de câmbio no comportamento dos preços de exportação dos setores analisados, bem como com relação às exportações totais. Cumpre salientar que os mencionados autores apontam como uma limitação deste estudo a agregação utilizada e sugerem que trabalhos futuros podem obter estimativas mais precisas analisando setores específicos.

Neste mesmo sentido, Correa (2012) avança e analisa os impactos de variações cambiais sobre os preços de exportação e os preços industriais domésticos, desagregados setorialmente, para o Brasil, entre 1995 e 2005 . O autor verificou maiores coeficientes de pass-through referentes aos preços de exportação em setores produtores de bens de menor conteúdo tecnológico e menores repasses dos choques de câmbio nos preços dos produtos manufaturados de maior intensidade tecnológica. Os coeficientes de pass-through associados aos preços domésticos superaram os preços de exportação, em sua maioria. Em relação aos preços industriais domésticos, os maiores coeficientes de repasse foram observados em setores produtores de manufaturados, geralmente importadores de componentes intermediários dotados de maior conteúdo tecnológico.

Correa (2012) não verificou diferenças significativas de repasses do câmbio aos preços exportados e domésticos para a maior parte dos setores analisados. O referido autor destacou, ainda, que os setores ligados à exportação de commodities e que não concentram suas vendas no mercado latino-americano e no americano foram menos afetados pela valorização cambial do Real.

É relevante destacar que mesmo o presente estudo tendo por objetivo avaliar a relação entre a taxa de câmbio real e o preço da carne de frango no Brasil, ou grau de exchange rate pass-through, 
não se pode considerar que as taxas de câmbio são totalmente exógenas às variações reais nos preços das commodities.

Deve-se levar em consideração, portanto, que estudos que envolvem política cambial e exportações em países em desenvolvimento, com destaque para commodities, não podem negligenciar a possibilidade de que as variáveis reais desempenham efeito sobre as taxas de câmbio. Os produtos primários dominam as exportações de países em desenvolvimento, logo, as flutuações nos preços mundiais desses bens têm o potencial para explicar uma grande parte dos movimentos em seus termos de troca. Na década de 2000, surgiram trabalhos empíricos que buscavam avaliar os mecanismos por meio dos quais as mudanças reais nos preços das commodities afetavam a taxa de câmbio real. Tais estudos não postulam que os preços reais dessas mercadorias têm um papel único na determinação da taxa de câmbio real, mas que os preços das commodities tendem a ser a mais importante fonte de persistentes mudanças na taxa de câmbio real dos países dependentes das exportações de tais bens. Este fenômeno é chamado na literatura econômica de commodity currencies (VERISSIMO, XAVIER e VIEIRA, 2012).

Destacam-se, neste sentido, os efeitos negativos da apreciação cambial causada pelas exportações de commodities sobre a indústria, em particular a teoria da "Doença Holandesa". Segundo esta teoria, a existência de vantagens naturais levaria ao crescimento das exportações de produtos de baixo valor agregado, como as commodities, o que acarretaria uma significativa entrada líquida de dólares na economia doméstica, resultando na apreciação da moeda local frente ao dólar e na redução da competitividade dos produtos com maior valor agregado, o que, por sua vez, prejudicaria a indústria nacional e induziria a um processo de "desindustrialização" (BRESSER-PEREIRA, 2008).

Margarido, Serigati e Perosa (2010) discutem o mecanismo de transmissão dos preços internacionais de commodities agrícolas para a taxa de câmbio real brasileira, no período entre janeiro de 2000 e fevereiro de 2010. Segundo os autores, a utilização de modelos de séries temporais para estimar as elasticidades de curto e longo prazo permite verificar, via função de transferência, que variações nos preços internacionais das commodities agrícolas são transmitidas para a taxa de câmbio real no Brasil no curto prazo, porém, essa transmissão é inferior à unidade, configurando uma relação inelástica.

Veríssimo, Xavier e Vieira (2012) discutem as evidências da presença da doença holandesa no Brasil e verificam a influência dos preços das diversas commodities exportadas sobre o comportamento de apreciação das taxas de câmbio nominal e real, ou commodity currency. Os autores utilizaram um modelo VEC e encontraram resultados que sinalizam a crescente importância dos produtos agrícolas no comportamento do câmbio. No período 1995-2009, as evidências de commodity currency são fracas; entretanto, no subperíodo 2003-2009, tais evidências se tornam mais robustas. Segundo os autores, a importância da análise dos efeitos dos preços de commodities específicas sobre a taxa de câmbio deve ser destacada, pois os mesmos verificam que os preços de alimentos, das matérias-primas e dos minerais parecem contribuir para a apreciação da taxa de câmbio nominal e real no período recente no Brasil.

\section{Metodologia}

O teste de raiz unitária utilizado foi o DickeyFuller Generalized Least Square (DF-GLS) conforme desenvolvido por Elliot; Rothenberg e Stock (1996). Essa metodologia, uma versão mais eficiente do tradicional Dickey-Fuller Aumentado (ADF), consiste na aplicação do teste ADF em séries de dados previamente filtrados de seus componentes determinísticos. Este procedimento mostra-se mais eficiente até mesmo em séries que possam apresentar uma média ou tendência não identificada ou desconhecida. O teste DF-GLS foi realizado em duas versões: com constante e ten- 
dência e somente com constante ${ }^{4}$ - modelos 1 e 2. O número de defasagens utilizadas foi determinado pelo Critério de Informação de Akaike Modificado (MAIC). Foram utilizados os valores críticos disponíveis em Elliot; Rothenberg e Stock (1996).

O grau de correlação e a existência de precedência temporal entre as variáveis foram testados utilizando-se a análise do Coeficiente de Correlação de Pearson e de Causalidade de Granger, respectivamente. Para duas séries de tempo $X_{t}$ e $Y_{t}$, o Coeficiente de Correlação de Pearson é dado por $\rho=\frac{\operatorname{cov}\left(X_{t}, Y_{t}\right)}{\sqrt{\operatorname{var}\left(X_{t}\right) \cdot \operatorname{var}\left(Y_{t}\right)}}$. A correlação mostra o grau de associação linear entre as variáveis.

O teste de Granger, por sua vez, consiste em assumir que a informação relevante para a predição das respectivas variáveis - $X_{t}$ e $Y_{t}-$, está contida apenas nas séries de tempo sobre essas duas variáveis e seus valores defasados (GRANGER, 1969). A realização de tal teste é justificada para corroborar o modelo teórico e, por conseguinte, a normalização do vetor de cointegração do modelo VEC.

Para estimar e analisar as relações de longo prazo estacionárias entre as variáveis, foi utilizado o teste de cointegração, tal como apresentado em Johansen (1988). O teste consiste na estimativa de um sistema que contém exatamente $h$ relações de cointegração por meio do método de Máxima Verossimilhança de Informação Plena (MVIP). A utilização da metodologia de Johansen contempla a possibilidade de existência de mais de um vetor de cointegração, assim como casos em que possa haver endogeneidade dos regressores. Para testar a presença de vetores de cointegração, utilizou-se a estatística $\lambda_{\text {traç }}$.

Foi utilizado, também, um Modelo Vetorial de Correção de Erros (VEC), para a realização da análise econômica do relacionamento tanto de

4 Modelo $1 \quad \Delta y_{t}^{\mu}=\beta_{0}+\beta_{1 t}+\alpha_{0} y_{t-1}^{\mu}+\sum_{j=1}^{p} \alpha_{j} \Delta y_{t-j}^{\mu}+\varepsilon$, na versão com constante e tendência.

Modelo $2 \Delta y_{t}^{\mu}=\beta_{0}+\alpha_{0} y_{t-1}^{\mu}+\sum_{j=1}^{p} \alpha_{j} \Delta y_{t-j}^{\mu}+\varepsilon$, na versão somente com constante. curto quanto de longo prazo entre as variáveis. Tal modelo pode ser representado por:

$$
\begin{aligned}
& \Delta x_{t}=\Gamma_{1} \Delta x_{t-1}+\ldots+\Gamma_{p-1} \Delta x_{t-p+1}+ \\
& +\Pi x_{t-1}+A_{0}+\psi D_{t}+\varepsilon_{t} \\
& \text { Com: } \\
& \Gamma_{i}=-\left(I-A_{1}-\ldots-A_{i}\right), i=(1, \ldots, p-1) \\
& \Pi=\left(I-A_{1}-\ldots-A_{p}\right)
\end{aligned}
$$

em que: $x_{t-i}$ é um vetor ( $\left.n \times 1\right)$ de variáveis estocásticas; $\Delta$ é um operador de diferenças; $\mathrm{D}_{t}$ é um vetor de variáveis determinísticas; $\varepsilon_{t} \sim N(0, \Sigma)$; $A_{i}$ é uma matriz de parâmetros $(n \times n)$ e I é uma matriz identidade $(n \times n)$.

Johansen (1988) propõe a decomposição da matriz $\Pi$ em:

$$
\Pi=\alpha \beta^{\prime}
$$

Desta relação, tem-se que o posto da matriz $\Pi$ define o número de vetores de cointegração, $\alpha$ representa a velocidade de ajustamento da matriz no curto prazo e $\beta^{\prime}$ é uma matriz de coeficientes de cointegração de longo prazo.

Também foram impostas restrições sobre o parâmetro de curto prazo $\alpha$ deste modelo com o objetivo de testar a presença de exogeneidade fraca. Busca-se testar se as variáveis reagem a mudanças na relação de equilíbrio de longo prazo (ENDERS, 2004).

A vantagem de se utilizar a metodologia VEC é que ela permite analisar as relações de longo prazo entre variáveis integradas e cointegradas, isto é, que sejam não estacionárias, mas tenham relação(ões) de equilíbrio de longo prazo. A utilização de modelos autorregressivos, do tipo VAR/ VEC, é recomendada quando se trabalha com modelos com poucas variáveis, uma vez que o viés de especificação é reduzido, pois a maior parte do efeito das variáveis explicativas omitidas é captada pelos termos autorregressivos e/ou média móvel (VANDAELE, 1983).

$\mathrm{O}(\mathrm{s})$ vetor(es) de cointegração fornece $(\mathrm{m})$ a elasticidade de longo prazo (as de curto prazo são fornecidas pela matriz de relações contemporânea e pela função de resposta a impulso), sendo 
possível também analisar o(s) coeficiente(s) de ajustamento $(\alpha)$ que mostra $(m)$ quanto do desequilíbrio de longo prazo é corrigido em cada período, podendo ser tomado como uma medida de velocidade de ajustamento. Ele(s) também permite $(\mathrm{m})$ testar a exogeneidade fraca (verificar se uma variável participa da relação de longo prazo) (ENDERS, 2004).

\section{Fonte de dados}

Os dados utilizados nesta pesquisa foram os preços do frango vivo, resfriado e congelado, em $\mathrm{R} \$ / \mathrm{kg}$, e a taxa de câmbio real, venda em $\mathrm{R} \$$ / US\$. Para os preços do frango (vivo, resfriado e congelado), utilizaram-se os dados da Fundação Getúlio Vargas (FGV) e, para as taxas de câmbio foram utilizadas as séries divulgadas pelo Instituto de Pesquisa Econômica Aplicada (Ipea).

Os preços, expressos em termos nominais, e a taxa de câmbio nominal foram transformados em valores reais utilizando o IGP-DI divulgado pela FGV.

A análise, feita com dados mensais, abrange o período de janeiro de 2008 a janeiro de 2012 . As séries utilizadas foram transformadas em logaritmo para o ajustamento do modelo; desta maneira, as relações entre as variáveis - valores dos coeficientes estimados - podem ser interpretadas diretamente na forma de elasticidades.
Os pacotes estatístico/econométrico utilizados foram o Regression Analysis of Time Series - RATS 6.2, utilizando as ferramentas do Cointegration Analysis of Time Series - CATS 2.0, e R 2.7.2.

\section{Resultados e discussão}

Os resultados dos testes de raiz unitária Dickey-Fuller Generalized Least Square (DF-GLS), apresentados na Tabela 1, levam a concluir que as séries preço do frango vivo (PFV), preço do frango resfriado (PFR), preço do frango congelado (PFC) e taxa de câmbio real (CAMR) são integradas de ordem um - I(1). Não se pode rejeitar a hipótese nula de que há uma raiz unitária nestas séries. Conclui-se, então, que é necessária a aplicação de uma diferença de ordem um para torná-las estacionárias.

Os testes de raiz unitária (Tabela 1) apontam que, em ambos os casos (modelos 1 e 2), com as variáveis em nível, não se pode rejeitar a hipótese nula de que há uma raiz unitária nas séries analisadas. Dado que as variáveis são integradas de ordem um, utilizou-se o procedimento de Johansen (Tabela 2) para estimar e testar as relações de longo prazo entre elas. Foi testada a existência de cointegração entre a taxa de câmbio real e os preços do frango vivo, resfriado e congelado - aos pares.

Tabela 1. Resultados dos testes de raiz unitária de Elliott-Rothenberg-Stock - DF-GLS - para as séries (em nível) utilizadas no modelo

\begin{tabular}{llccc}
\hline \multicolumn{1}{c}{ Variável } & \multicolumn{1}{c}{ Modelo 1 } & Modelo 2 \\
\cline { 2 - 5 } & $p$ & Estatística DF-GLS & $p$ & Estatística DF-GLS \\
\hline Preço do frango vivo & 0 & $-2,35^{* *}$ & 0 & $-2,00^{*}$ \\
Preço do frango resfriado & 0 & $-2,42^{* *}$ & 6 & $-1,40^{* *}$ \\
Preço do frango congelado & 0 & $2,78^{* *}$ & 0 & $-2,43^{*}$ \\
Taxa de câmbio real & 1 & $-2,64^{* *}$ & 1 & $-0,80^{* *}$ \\
\hline
\end{tabular}

* Não significativo ao nível de 0,05 de probabilidade; ** Não significativo ao nível de 0,10 de probabilidade.

Fonte: Elaborado pelos autores com dados da pesquisa. 
Tabela 2. Resultados do teste de cointegração de Johansen

\begin{tabular}{|c|c|c|c|c|c|c|c|}
\hline \multirow{2}{*}{$\begin{array}{c}\text { Hipótese } \\
\text { Nula } \\
H_{0}\end{array}$} & \multirow{2}{*}{$\begin{array}{c}\text { Hipótese } \\
\text { Alternativa } \\
H_{\mathrm{A}}\end{array}$} & \multicolumn{2}{|c|}{$\begin{array}{l}\text { Câmbio real e preço do } \\
\text { frango vivo }\end{array}$} & \multicolumn{2}{|c|}{$\begin{array}{l}\text { Câmbio real e preço do } \\
\text { frango resfriado }\end{array}$} & \multicolumn{2}{|c|}{$\begin{array}{l}\text { Câmbio real e preço do } \\
\text { frango congelado }\end{array}$} \\
\hline & & Eigenvalue & Estatística Traço & Eigenvalue & Estatística Traço & Eigenvalue & Estatística Traço \\
\hline $\mathrm{r} \leq 1$ & $r=2$ & 0,040 & 2,43 & 0,039 & 2,36 & 0,042 & 2,60 \\
\hline $\mathrm{r}=0$ & $\mathrm{r}=1$ & 0,178 & 14,80 & 0,237 & 18,58 & 0,318 & $25,56^{*}$ \\
\hline
\end{tabular}

* Significativo ao nível de 0,05 de probabilidade.

Fonte: Elaborado pelos autores com dados da pesquisa.

Os resultados do teste de Johansen (Tabela 2) apontam que só existe cointegração entre as variáveis câmbio real e preço do frango congelado. $\mathrm{O}$ teste, por meio da estatística traço $(\lambda)$, indica que existe um vetor de cointegração entre tais variáveis; considerou-se o nível de significância de $5 \%$ de probabilidade. O modelo foi ajustado com uma constante fora do espaço de cointegração e uma defasagem. A significância da constante no vetor de cointegração foi testada (distribuição $\chi^{2}$ ) e não se rejeitou a hipótese de ela ser nula. Testou-se também a inclusão de uma tendência no vetor de cointegração, e a hipótese nula de que o coeficiente dessa variável seja igual a zero não foi rejeitada.
Portanto, os resultados encontrados (Tabela 2) sinalizam que as variáveis câmbio real e preço do frango congelado apresentam equilíbrio de longo prazo estável e são, portanto, consideradas cointegradas. Desta forma, as relações existentes entre tais variáveis são estabelecidas utilizando um modelo Vetorial de Correção de Erros (VEC).

Antes da estimativa do modelo VEC, apresentam-se a matriz de correlações (Figura 3) coeficientes de correlação de Pearson - e o teste de causalidade de Granger (Tabela 3). Estudos como os de Aguiar e Santana (2002) e Kannebley Junior (2002) também analisam previamente a causalidade no sentido de corroborar o modelo teórico.

Figura 3. Matriz de correlações entre as variáveis - nas diferenças
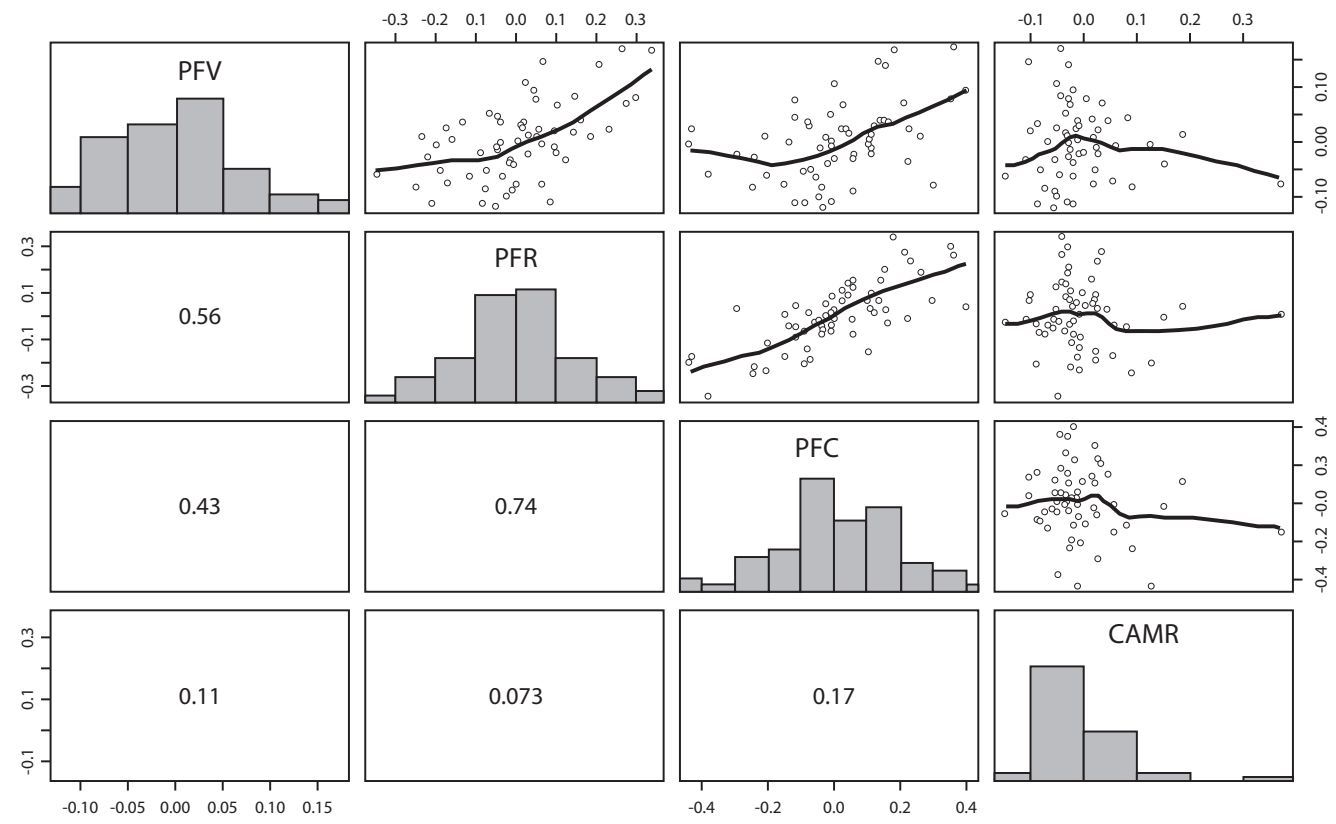

Nota: As variáveis estão na primeira diferença.

Fonte: Elaborado pelos autores com dados da pesquisa. 
A Figura 3 mostra a representação gráfica da correlação entre as variáveis na triangular superior da matriz - analisada aos pares; as distribuições de cada variável na diagonal principal; e os valores do coeficiente de correlação de Pearson na triangular inferior - aos pares.

Observa-se (Figura 3) que existe uma correlação elevada entre preço do frango resfriado e o preço do frango congelado $(0,74)$ e uma correlação mediana entre os preços do frango vivo e o preço do frango resfriado $(0,56)$. No que tange às relações entre os preços da carne de frango e a taxa de câmbio real, o observado foi uma correlação baixa entre o preço do frango congelado e a taxa de câmbio real $(0,17)$ e entre o preço do frango vivo e a taxa de câmbio real $(0,11)$.

$\mathrm{Na}$ Tabela 3, são apresentados os resultados do teste de causalidade de Granger entre as variáveis. Os resultados do teste de causalidade apontam relações causais no sentido inverso à hipótese inicial deste estudo. No caso da hipótese nula, em que o preço do frango vivo não causa a taxa de câmbio real, versus a hipótese alternativa de existência de causalidade, verificou-se que a hipótese nula foi rejeitada - com um nível de significân- cia de $10 \%$ de probabilidade e com uma defasagem. Observa-se, também, no caso do preço do frango resfriado (com uma e duas defasagens) e do preço do frango congelado (com uma, duas e três defasagens), que a hipótese nula de que essas variáveis não causam a taxa de câmbio real foi rejeitada.

Esses resultados (Tabela 3) mostram uma precedência temporal no sentido de que os preços de frango vivo, resfriado e congelado precedem as variações na taxa de câmbio real. Estudos como os de Bresser-Pereira (2008), Margarido, Serigati e Perosa (2010) encontram resultados semelhantes, entretanto, analisando o quantum exportado, no que se convencionou chamar de "Doença Holandesa", esses estudos observam o efeito de commodities específicas sobre as taxas de câmbio nominal e real.

Autores como Fernandez (2003), Clements e Fry (2006), Hampshire (2008) e, recentemente, Veríssimo, Xavier e Vieira (2012) também analisam os efeitos da expansão do mercado de commodities sobre a taxa de câmbio, ou ainda commodities currencies. Esta denominação é dada às moedas de países cujos valores estão forte-

Tabela 3. Teste de causalidade de Granger entre as variáveis

\begin{tabular}{lccc}
\hline \multirow{2}{*}{\multicolumn{1}{c}{ Hipótese nula do teste }} & 1 defasagem & 2 defasagens & 3 defasagens \\
\cline { 2 - 4 } & Estatística $F$ & Estatística $~$ & Estatística $F$ \\
\hline PFR não causa PFV & 0,21 & 0,16 & 0,24 \\
PFV não causa PFR & 1,65 & 1,39 & 1,24 \\
PFC não causa PFV & 2,16 & 0,57 & 0,51 \\
PFV não causa PFC & 2,42 & 1,68 & 1,09 \\
CAMR não causa PFV & 0,72 & 1,43 & 1,09 \\
PFV não causa CAMR & $3,34^{* * *}$ & 1,38 & 1,58 \\
PFC não causa PFR & 2,35 & 2,27 & 1,61 \\
PFR não causa PFC & $2,82^{* *}$ & $4,66^{*}$ & $3,00^{* *}$ \\
CAMR não causa PFR & 0,007 & 0,77 & 0,83 \\
PFR não causa CAMR & $7,95^{*}$ & $2,43^{* *}$ & 1,74 \\
CAMR não causa PFC & 0,003 & 0,09 & 1,31 \\
PFC não causa CAMR & $15,26^{*}$ & $4,90^{*}$ & $3,37^{* *}$ \\
\hline
\end{tabular}

Nota: A expressão "não causa", utilizada como hipótese nula do teste, deve ser entendida no sentido de causalidade de Granger. O teste de Granger mostra a existência de precedência temporal entre variáveis, não necessariamente causa e efeito.

* Significativo ao nível de 0,01 de probabilidade.

** Significativo ao nível de 0,05 de probabilidade.

**** Significativo ao nível de 0,10 de probabilidade.

Fonte: Elaborado pelos autores com dados da pesquisa. 
Tabela 4. Estimativa dos coeficientes de curto e de longo prazo do Modelo Vetorial de Correção de Erros (VEC)

\begin{tabular}{clcc}
\hline & Variáveis & $\begin{array}{c}\text { Estimativa dos coeficientes } \\
\text { de ajuste de curto prazo } \alpha\end{array}$ & $\begin{array}{c}\text { Estimativa dos coeficientes } \\
\text { de longo prazo } \beta\end{array}$ \\
\hline \multirow{2}{*}{ I } & Taxa de câmbio real & $-0,043^{*}$ & 1,000 \\
& Preço do frango congelado & $0,003^{*}$ & $5,88^{*}$ \\
\hline \multirow{2}{*}{ II } & Preço do frango congelado & $-0,228^{*}$ & 1,000 \\
& Taxa de câmbio real & $0,251^{*}$ & $0,170^{* *}$ \\
\hline
\end{tabular}

Nota: O modelo VEC foi estimado com 1 (uma) defasagem, de acordo com o SBC (Schwarz Bayesian Criterion); trata-se de um modelo mais parcimonioso e que implica em menor perda de graus de liberdade.

* Significativo ao nível de 0,01 de probabilidade.

** Significativo ao nível de 0,10 de probabilidade.

Fonte: Elaborado pelos autores com dados da pesquisa.

mente atrelados a variações nos preços das exportações. Para o Brasil, a existência de tal fenômeno é testada empiricamente por Veríssimo, Xavier e Vieira (2012), que destacam que, para o período mais recente - 2003-2009-, as evidências do fenômeno mostram-se mais robustas.

$\mathrm{Na}$ sequência, são apresentadas as estimativas dos coeficientes de curto e longo prazo do modelo VEC (Tabela 4). Os resultados apresentados referem-se à equação de cointegração normalizada. A normalização foi efetuada inicialmente (I) considerando-se a variável taxa de câmbio real como variável de saída do modelo (endógena), enquanto a variável preço do frango congelado foi considerada a variável de entrada (exógena), como sugere o teste de Granger. Em (II), foi considerada a variável preço do frango congelado como endógena e a taxa de câmbio real como exógena, de acordo com a hipótese inicial deste estudo.

A estimativa do coeficiente de longo prazo $\beta$ para a variável preço do frango congelado $(I)$ mostra que, a cada $1 \%$ de variação no preço do frango congelado, a taxa de câmbio (R\$/US\$) varia cerca de $-5,88 \%{ }^{5}$ - uma apreciação do Real. O coeficiente estimado é significativo a $1 \%$ de probabilidade. Esse resultado sugere que um contexto de elevação dos preços das commodities, decorrente de um cenário de expansão na demanda mundial

5 Cumpre mencionar que, devido à normalização efetuada no vetor de cointegração, a análise da estimativa do coeficiente deve ser conduzida com o sinal invertido, pois, na equação de cointegração normalizada, todas as variáveis permanecem do mesmo lado da equação (ENDERS, 2004). por produtos agrícolas, por exemplo, pode contribuir para uma taxa de câmbio real brasileira mais apreciada no período recente. O resultado é semelhante ao apresentado por Fernandez (2003) e Veríssimo, Xavier e Vieira (2012), que observam que a taxa de câmbio real no Brasil aprecia-se em resposta a elevações nos preços internacionais dos principais segmentos exportadores de commodities.

Quanto à estimativa do coeficiente de longo prazo $\beta$, para a variável taxa de câmbio real (II), observa-se que a magnitude deste coeficiente $(-0,17)$ é sensivelmente menor - uma apreciação real da moeda doméstica aumenta o preço da mercadoria - que o observado quando a variável taxa de câmbio real é considerada endógena. Tem-se, então, que o câmbio real é mais afetado pelo preço do frango congelado que o preço do frango congelado pelas taxas de câmbio. O resultado é semelhante ao encontrado por Tejada e Silva (2008), em análise da relação entre câmbio e o preço dos principais produtos brasileiros exportados, no período de 1980-2004. Os resultados desses autores mostram um efeito exchange rate pass-through baixo para a economia brasileira. Uma justificativa para o resultado poder ser encontrada em Correa (2012), que considera que o coeficiente de pass-through entre câmbio e preços de commodities é maior quanto maior o grau de abertura do setor, assim como é menor quanto maior a concorrência internacional do setor.

Os parâmetros de curto prazo estimados $\alpha$ (Tabela 4) mostram uma baixa velocidade de ajuste em direção ao equilíbrio de longo prazo 
diante de desequilíbrios transitórios - curto prazo -, quando a variável taxa de câmbio real é considerada endógena. Os coeficientes estimados revelam que os preços da carne de frango tendem a se ajustar a uma taxa de $0,3 \%$ em cada período e, no mercado de câmbio, o ajuste é de 4,3\%. Por outro lado, quando o preço da carne de frango é considerado endógeno, o ajuste é de 22,8\% e $25,1 \%$, respectivamente, para o preço do frango congelado e taxa de câmbio real. O que justifica, em parte, esse resultado, é o fato de o mercado de câmbio apresentar maior dinamismo em suas negociações, relativamente aos mercados agropecuários.

Com o objetivo de avaliar se as variáveis reagem em função de alterações no equilíbrio de longo prazo, foi realizado o teste de exogeneidade fraca sobre os parâmetros $\alpha$ (Tabela 5). A análise do teste de exogeneidade fraca, neste caso, permite que se verifique o sentido de causalidade na relação de cointegração. Tenciona-se testar se a causalidade observada é unidirecional ou se existe causalidade em ambos os sentidos - bicausalidade.

Em relação às variáveis preço do frango congelado e taxa de câmbio real, o resultado do teste de exogeneidade fraca (Tabela 5) aponta, em ambos os casos, a rejeição da hipótese nula, ou seja, as variáveis não podem ser consideradas fracamente exógenas, considerando $1 \%$ de probabilidade. Esse resultado mostra que a causalidade observada é bidirecional. Destaca-se, portanto, que nesta relação de cointegração, os preços do frango congelado influenciam o comportamento da taxa de câmbio real no Brasil, em que, por outro lado, a relação inversa também pode ser verificada.

A relação bidirecional entre os preços do frango congelado no Brasil e as taxas de câmbio real evidencia dois fatos. Por um lado, sinaliza a existência do fenômeno chamado commodity currency, apontado por Fernandez (2003), Clements e Fry (2006), Hampshire (2008) e Veríssimo, Xavier e Vieira (2012) como a relação entre as taxas de câmbio de um país e os preços das commodities de exportação. A magnitude do coeficiente de longo prazo do modelo VEC mostra que essa relação entre preço do frango congelado e taxas de câmbio real é elevada - elástica - e estatisticamente significativa. Por outro lado, esta relação bidirecional evidencia um segundo fato, qual seja, de que o preço da carne de frango congelada no País, mesmo inelástico às taxas de câmbio real, não se mostra totalmente insensível às variações no câmbio. Resultados semelhantes, todavia, para setores exportadores, foram apresentados por Kannebley Junior (2002), Tejada e Silva (2008) e, mais recentemente, por Correa (2012), evidenciando-se um baixo grau de pass-through para o valor das commodities brasileiras em relação à taxa de câmbio real, além de um alcance limitado da política cambial sobre a competitividade de setores exportadores.

Evidências de commodity currency no Brasil são apresentadas empiricamente por Veríssimo, Xavier e Vieira (2012). O estudo desses autores sugere a importância da análise dos efeitos dos preços de grupos de commodities específicas alimentos, matérias-primas, minerais e energia sobre a taxa de câmbio, pois, quando tomados os preços de alimentos, das matérias-primas e dos minerais, os resultados deste estudo indicam que tais variáveis parecem contribuir para uma apreciação da taxa de câmbio nominal e real no período de 2005 a 2009.

Por fim, cumpre chamar a atenção para uma limitação deste estudo, pelo fato de o modelo estimado considerar apenas a relação entre a taxa

Tabela 5. Resultados do teste de exogeneidade fraca

\begin{tabular}{lcc}
\hline \multicolumn{1}{c}{ Variáveis } & $\chi^{2}$ & Valor da probabilidade \\
\hline Preço do frango congelado & 6,77 & 0,009 \\
Taxa de câmbio real & 14,95 & 0,000 \\
\hline
\end{tabular}

Fonte: Elaborado pelos autores com dados da pesquisa. 
de câmbio e o preço da carne de frango, deve-se distinguir o efeito total do efeito direto da taxa de câmbio sobre o preço da carne de frango. No entanto, embora a ausência de variáveis possa constituir-se um problema de especificação, acredita-se que o viés seja pequeno, pois, como bem fundamentado em Vandaele (1983), em modelos de séries temporais como VAR/VEC, a maior parte do efeito de variáveis explicativas omitidas é captada pelos termos autorregressivos, considerando que tais efeitos estejam refletidos no passado histórico da série.

\section{Conclusões}

O objetivo principal deste estudo foi avaliar a relação entre taxa de câmbio real e os preços da carne de frango no Brasil, no período de 2008 a 2012, analisando o relacionamento de curto e longo prazo entre essas variáveis. Buscou-se mensurar a elasticidade de transmissão de preços entre taxa de câmbio real e preço da carne de frango no mercado doméstico, ou, ainda, o grau de exchange rate pass-throught para o setor.

Os resultados do teste de causalidade de Granger apontaram a rejeição da hipótese inicial do estudo - existência de precedência temporal da taxa de câmbio em relação aos preços da carne de frango -, sugerindo, por outro lado, a causalidade no sentido inverso, o que evidencia a existência de commodity currency no Brasil.

Quando analisada a cointegração entre as séries de preços de frango vivo, resfriado e congelado, e a taxa de câmbio real, os resultados apontaram a existência de relação estável de longo prazo, apenas entre a taxa de câmbio e os preços da carne de frango congelada, o que leva a concluir que existe cointegração do preço do frango em relação à taxa de câmbio somente no segmento mais relevante em termos de exportação de carne de frango.

Em termos de transmissão das variações, o estudo apontou que a taxa de câmbio real no Brasil apresentou-se elástica em relação às variações no preço da carne de frango congelada, o que evidencia uma sensibilidade desta variável em relação aos movimentos no mercado de commodities específicas no País. Por outro lado, mesmo inelástico, o preço da carne de frango congelada apresentou relação com as variações na taxa de câmbio, ou seja, um baixo grau de pass-through. Em suma, a relação é bicausal entre as variáveis.

A contribuição deste estudo está em mostrar a relevância de um setor específico no contexto das taxas de câmbio no Brasil, mesmo não sendo o objetivo inicial deste artigo. Os resultados apontaram a existência do fenômeno chamado commodity currency, já evidenciado para a economia brasileira, entretanto, não analisado por estudos anteriores para segmentos exportadores específicos. Os resultados permitem, também, que se evidencie a relevância do setor exportador para a apreciação das taxas de câmbio do Real em relação ao dólar norte-americano, nos últimos anos.

Com base nos resultados deste estudo, pode-se concluir que o efeito da política cambial, como medida de competitividade, tem alcance limitado no mercado de carne de frango no País, dado o baixo grau de pass-through existente, bem como que a questão de elevação de preços domésticos de bens exportáveis não é perfeitamente explicada pelos movimentos no mercado de câmbio. Por outro lado, conclui-se, também, que a política cambial não pode ignorar o comportamento dos preços de commodities exportadas pelo País, uma vez que o estudo sinaliza tais preços como um fator de influência.

Estudos futuros podem contemplar a análise dos principais segmentos exportadores do Brasil e a influência de cada um destes levando em consideração a parcela de tais segmentos nas exportações nacionais, ou seja, analisar se os setores com maior relevância na pauta de exportação têm influência maior na taxa de câmbio.

\section{Referências bibliográficas}

ASSOCIAÇÃO BRASILEIRA DOS PRODUTORES E EXPORTADORES DE FRANGOS - ABEF. 2012. Dados estatísticos. Disponível em: <http://www.abef.com. br/>. Acesso em: 20 mar. 2012. 
AGUIAR, D. e SANTANA, J. A. Asymmetry in farm to retail price transmission: evidence for Brazil. Agribusiness, v. 18, n. 1, p. 37-48, 2002.

ALDERMAN, $\mathrm{H}$. Intercommodity price transmittal: analysis of food markets in Ghana. Working Paper 884. World Bank, Washington, USA. 1992.

BRESSER-PEREIRA, L. C. The Dutch Disease and its Neutralization: a Ricardian Approach. Revista de Economia Política, São Paulo, v. 28, n. 1 (109), p. 47-71, jan./mar. 2008.

CLEMENTS, K. W. e FRY, R. Commodity Currencies and Currency Commodities. Economics Discussion / Working Papers 06-17, The University of Western Australia, Department of Economics, jul. 2006.

CORREA, A. L. Taxa de câmbio e preços de exportação no Brasil: avaliação empírica dos coeficientes de passthrough setoriais. Economia e Sociedade, Campinas, v. 21, n. 1 (44), p. 61-91, abr. 2012.

DORNBUSCH, R. Inflação, taxas de câmbio e estabilização. Pesquisa e planejamento econômico. Rio de Janeiro, v. 16, n. 2, p. 321-350, ago. 1986

ELLIOT, G., ROTHENBERG, T. J. e STOCK, J. H. Efficient tests for an autoregressive unit root. Econometrica, Oxford, v. 64, n. 4, 1996.

EMPRESA BRASILEIRA DE PESQUISA AGROPECUÁRIA - EMBRAPRA. Embrapa suínos e aves. Disponível em: <http://www.cnpsa.embrapa.br>. Acesso em: 12 nov. 2011.

ENDERS. W. Applied Econometric Time Series. 2. ed. New Jersey: John Wiley Sons, 2004. 480 p.

FERNANDEZ, C. Y. H. Câmbio Real e Preços de Commodities: Relação Identificada Através da Mudança de Regime Cambial. Rio de Janeiro. Dissertação de Mestrado. Pontifícia Universidade Católica. Departamento de Economia. 86p. 2003.

FOOD AGRICULTURE ORGANIZATION OF THE UNITED NATIONS - FAO. Commodities and markets. Disponivelem: $<$ http://www.fao.org/worldfoodsituation/ wfs-home/en/> . Acesso em: 15 mar. 2012.

FUNDAÇÃO GETÚLIO VARGAS - FGV. Disponível em: $<$ http://www.agroanalysis.com.br/index.php?area= mercadonegocios >. Acesso em: 15 jan. 2012.

GRANGER, C. Investigating causal relations by econometric models and cross-spectral methods, Econometrica, Oxford, v. 37, p. 424-438, 1969.

HAMPSHIRE, B. N. O Efeito de Preços de Commodities sobre a Taxa de Câmbio Real para Países Exportadores de
Commodities: Uma Análise Empírica. Rio de Janeiro. Dissertação de Mestrado. Pontifícia Universidade Católica do Rio de Janeiro. Departamento de Economia. 80p, 2008.

INSTITUTOPARANAENSEDEDESENVOLVIMENTO ECONÔMICO E SOCIAL - IPARDES. Análise da competitividade da cadeia agroindustrial de frango mo estado do Paraná. Sumário executivo, Curitiba: IPARDES, 2002.

IPEADATA. Base de Dados do Instituto de Pesquisa em Economia Aplicada - IPEA. Macroeconômico. Disponível em: http://www.ipeadata.gov.br/ipeaweb.dll/ ipeadata?192810671. Acesso em: 15 jan. 2012.

JOHANSEN, S. Statistical analysis of cointegration vectors. Journal of Economic Dynamics and Control, Boston, v. 12, p. 231-54, 1988.

KANNEBLEY JUNIOR, S. Desempenho exportador brasileiro recente e taxa de câmbio real: uma análise setorial. Revista Brasileira de Economia. Rio de Janeiro, v. 56, n. 3, p. 429-456, jul./set. 2002.

MARGARIDO, M. A., SERIGATI, F. C. e PEROSA, B. B. Análise do mecanismo de transmissão dos preços internacionais de commodities agrícolas sobre o comportamento da taxa de câmbio real no Brasil. Textos para discussão TD 256, São Paulo: EESP/FGV, Mai, 2010.

MINISTÉRIO DA AGRICULTURA, PECUÁRIA E ABASTECIMENTO - MAPA. Intercâmbio comercial do agronegócio: principais mercados de destino. Brasília: MAPA/ACS, 2011.

MINISTÉRIO DO DESENVOLVIMENTO INDÚSTRIA E COMÉRCIO EXTERIOR - MIDIC/SECEX. Alice web: dados das Exportações brasileiras por destino. Disponível em: $\quad<$ http://www.aliceweb.desenvolvimento.gov.br>. Acesso em: 15 fev. 2012.

SILVA, C. R. L. e CARVALHO, M. A. Taxa de Câmbio e preços de Commoditties agrícolas. Informações econômicas, São Paulo, v. 5, n. 5, p. 23-35, mai. 1995.

SISTEMA DO INSTITUTO BRASILEIRO DE GEOGRAFIA E ESTATÍSTICA DE RECUPERAÇÃO AUTOMÁTICA - SIDRA/IBGE. Produção Agrícola Municipal. Disponível em: <http://www.sidra.ibge.gov. br/bda/acervo/acervo2 > . Acesso em: 14 dez. 2011.

SONAGLIO, M. C., ZAMBERLAM, C. O. e BENDER FILHO, R. Variações cambiais e os efeitos sobre exportações brasileiras de soja e carnes. Revista de Política Agrícola, Brasília, v. 20, n. 1, p. 5-23, jan./mar. 2011.

TEJADA, C. A. O. e SILVA, A. G. O pass-through das variações da taxa de câmbio para os preços dos principais produtos exportados pelo Brasil. Revista de 
Economia e Sociologia Rural. Piracicaba, v. 46, n. 1, p. 171205, jan./mar. 2008.

VANDAELE, W. Applied Time Series and Box-Jenkins Models. Orlando: Florida, Academic Press, Inc. (London) Ltda, 1983. 417p.
VERISSIMO, M. P., XAVIER, C. L. e VIEIRA, F. V. Taxa de câmbio e preços de commodities: uma investigação sobre a hipótese da Doença Holandesa no Brasil. Revista Economia, Brasília, v. 13, n. 1, p. 93-130, jan./abr. 2012. 